\title{
Developing an Asthma Self-management Intervention Through a Web-Based Design Workshop for People With Limited Health Literacy: User-Centered Design Approach
}

Hani Salim ${ }^{1,2^{*}}$, MMed; Ping Yein Lee ${ }^{3 *}$, MMed; Sazlina Sharif-Ghazali ${ }^{2,4 *}, \mathrm{PhD}$; Ai Theng Cheong ${ }^{2 *}, \mathrm{PhD}$; Jasmine Wong $^{2^{*}}$, MBBS; Ingrid Young ${ }^{5 *}, \mathrm{PhD}$; Hilary Pinnock ${ }^{1 *}, \mathrm{MD}$; RESPIRE Collaboration ${ }^{1}$

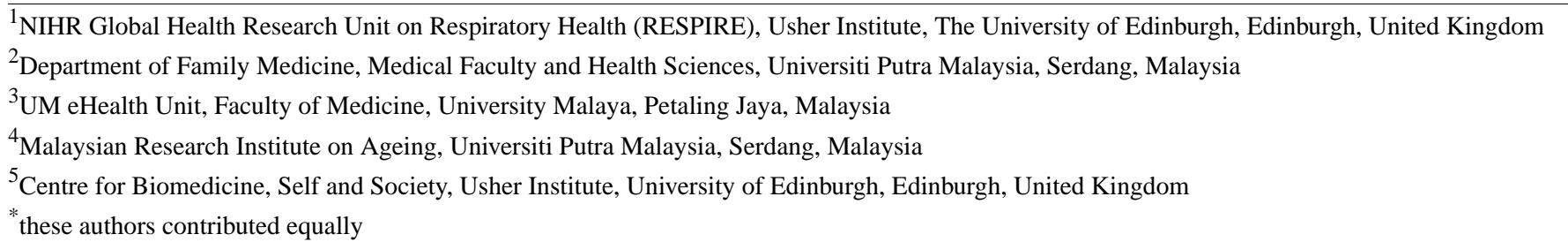

\section{Corresponding Author:}

Hilary Pinnock, MD

NIHR Global Health Research Unit on Respiratory Health (RESPIRE)

Usher Institute

The University of Edinburgh

Old Medical School

Doorway 3, Teviot Place

Edinburgh, EH8 9AG

United Kingdom

Phone: 44013165094

Email: hilary.pinnock@ed.ac.uk

\section{Abstract}

Background: Technology, including mobile apps, has the potential to support self-management of long-term conditions and can be tailored to enhance adoption. We developed an app to support asthma self-management among people with limited health literacy in a web-based workshop (to ensure physical distancing during the COVID-19 pandemic).

Objective: The aim of this study is to develop and test a prototype asthma self-management mobile app tailored to the needs of people with limited health literacy through a web-based workshop.

Methods: We recruited participants from a primary care center in Malaysia. We adapted a design sprint methodology to a web-based workshop in five stages over 1 week. Patients with asthma and limited health literacy provided insights into real-life self-management issues in stage 1, which informed mobile app development in stages $2-4$. We recruited additional patients to test the prototype in stage 5 using a qualitative research design. Participants gave feedback through a concurrent thinking-aloud process moderated by a researcher. Each interview lasted approximately 1 hour. Screen recordings of app browsing activities were performed. Interviews were audio-recorded and analyzed using a thematic approach to identify utility and usability issues.

Results: The stakeholder discussion identified four themes: individual, family, friends, and society and system levels. Five patients tested the prototype. Participants described 4 ways in which the app influenced or supported self-management (utility): offering information, providing access to an asthma action plan, motivating control of asthma through support for medication adherence, and supporting behavior change through a reward system. Specific usability issues addressed navigation, comprehension, and layout.

Conclusions: This study proved that it was possible to adapt the design sprint workshop to a web-based format with the added advantage that it allowed the development and the testing process to be done efficiently through various programs. The resultant app incorporated advice from stakeholders, including sources for information about asthma, medication and appointment reminders, accessible asthma action plans, and sources for social support. The app is now ready to move to feasibility testing.

(J Med Internet Res 2021;23(9):e26434) doi: $10.2196 / 26434$ 


\section{KEYWORDS}

asthma; self-management; design sprint; health literacy; mobile phone

\section{Introduction}

\section{Background}

Supported self-management for asthma (written action plans and regular review) is highly effective at improving control and reducing acute attacks [1-3]; however, globally, it is challenging to implement for 334 million people living with asthma [4-7]. One of the challenges is the need to tailor support for people with limited health literacy. Health literacy is defined as the degree to which individuals can obtain, process, and understand the necessary health information needed to make appropriate health decisions [8]. Studies have associated limited health literacy with erroneous health beliefs and poor adherence to self-management activities $[9,10]$. Malaysia has a high burden of limited health literacy in the general population [11], and asthma control is challenged by a lack of patient education, overreliance on unscheduled visits, and lack of action plan ownership [12-14].

The use of digital technologies for internet-based information is more common in the younger age group than in the middle and older age groups [15]. Malaysia's multigenerational household culture and strong family orientation have helped younger family members assist older generations in using digital technology to stay connected and find information [16]. The pandemic has further seen widespread adoption of digital technologies by a broader age group of users in diagnosis, prevention, and surveillance [17]. Three-fourth of Malaysians are now smartphone users, with most $(60.9 \%)$ of them in the lowest income group [18]. Although health-related information-seeking behavior on the internet is greater in those with good health literacy [19], our previous qualitative work among people with limited health literacy suggests that a mobile app is a preferred medium to deliver supported self-management, including a pictogram-based asthma action plan and signposting to reliable asthma information sources.

\section{Goals}

For the aforementioned reasons, developing asthma self-management tailored to limited health literacy needs is an important context for the web-based design sprint workshop, as various studies have shown that the extensive use of pictograms, images, and prompts was appealing to participants and may improve the understanding of information in mobile apps [20-23]. However, it is essential to involve users early in the design stage, as some of the unique features that people want can be time-consuming and costly to build, and a balance may need to be found between desired features [24] and those with evidence-based recommendations $[25,26]$.
Using a design sprint methodology, we seek to optimize user experience in app development by integrating patients into the 5-stage process of mapping, sketching, designing, developing, and testing [24,27]. We used the health literacy framework [8] to underpin the overall structure of the interventional work. The COVID-19 pandemic and physical distancing requirements meant that we had to conduct our workshop in a web-based format. In this study, we report the outcomes of the workshop deliberations and our experience of conducting a week-long remote 5 -stage program attended by patients with asthma and health care professionals (HCPs).

\section{Methods}

\section{Ethical Consideration}

The workshop received ethical approval from the Medical Research and Ethics Committee of the Ministry of Health, Malaysia (ID: NMRR-19-3609-52292) and sponsorship approval by the Academic and Clinical Central Office for Research \& Development at the University of Edinburgh (ID: AC20011). Informed consent was obtained from all the participants before the workshop.

\section{Study Design}

We conducted a 5-stage design sprint workshop using a web-based and qualitative research approach. We used the 5-stage design sprint process as a roadmap to develop the intervention. We adapted the methodology and constructed the workshop into five stages: (1) understanding and mapping problems, (2) sketching of solutions, (3) deciding on solutions to problems, (4) developing a prototype, and (5) testing a low-fidelity prototype $[27,28]$. The process was originally designed in the technology sector by the Google Ventures team for business start-up teams [27]. The involvement of the target population and early testing enhance intervention effectiveness and increase the likelihood of adoption at the implementation stage [24]. Owing to the rapid development and testing stages, this is an ideal concept for a low-resource setting, that is, time and cost [24].

Stakeholder (patient and HCP) discussions provided insights into self-management issues in stage 1 , which informed mobile app development in stages 2-4. We recruited patients with asthma and limited health literacy to test the low-fidelity prototype in stage 5 and provided feedback through qualitative interviews. A low-fidelity prototype is a modeled prototype with limited technical functionality [29] that is quick to create and can be easily improved in the light of feedback in the testing stages. The details of each stage are listed in Table 1. 
Table 1. Process, outcomes, and web-based adaptations of the workshop.

\begin{tabular}{|c|c|c|}
\hline Stages and objectives & Process & Adaptations for web-based delivery of the workshop \\
\hline \multicolumn{3}{|c|}{ Stage 1: understand and mapping problem } \\
\hline $\begin{array}{l}\text { - To identify the objectives } \\
\text { of the prototype and the } \\
\text { workshop } \\
\text { To map out problems from } \\
\text { health care professionals } \\
\text { and patients' perspectives } \\
\text { which technology can help } \\
\text { to solve }\end{array}$ & $\begin{array}{l}\text { As a team, we first discussed and agreed on the } \\
\text { workshop's long-term goals for the workshop's } \\
\text { prototype and aims through a structured discus- } \\
\text { sion between the patients and health care profes- } \\
\text { sionals. } \\
\text { We listed a list of problems relating to self-man- } \\
\text { aging asthma from stakeholders (patients and } \\
\text { clinicians) point of views. } \\
\text { We constructed an end-to-end process of how } \\
\text { patients cared for their asthma, and we targeted }\end{array}$ & $\begin{array}{l}\text { Through a web conference site (Microsoft Teams), } \\
\text { we brainstormed the long-term goal for the app } \\
\text { and the workshop's aim. } \\
\text { In a separate browser, using a web-based board } \\
\text { (Miro), we gathered the problems, potential solu- } \\
\text { tions, and mapping of the target where the solutions } \\
\text { can occur. Interviews were audio recorded during } \\
\text { the workshop. } \\
\text { We considered scientific literature and previous } \\
\text { study we have conducted as expert input. }\end{array}$ \\
\hline
\end{tabular}

\section{Stage 2: sketch solution}

- $\quad$ To understand a broad range of problems and solutions concerning asthma self-management
- Focusing on the problems, each researcher reviewed existing ideas which we could potentially use and improve for the prototype.

- The individual researcher then presented their findings and the reasons why the ideas being chosen.

- Using this information, we then drew crude scenes with our contents which we believed would be suitable for the app.

- After presenting the scenes and critical discussions, we voted on the best scene and content for the prototype.

\section{Stage 3: decide the solution for the problem}

- $\quad$ To decide on solutions that answered our longterm objectives
- The winning scenes and content comprised topics on asthma education, asthma symptoms monitoring, and supporting people living with asthma.

- We took the winning scenes from our sketches, and we constructed an end-to-end process (storyboard) on how these scenes and content would appear on an App.

- The storyboard was first constructed in text form before we transformed it visually.
- Reviewing and compiling sketches of ideas were done on Miro synchronously by all researchers.

- We presented these sketches of ideas to the whole team on Microsoft Teams.

- Individually, using colorful sticky notes and marker pens, we drew the crude scenes. We took photographs of these scenes and uploaded these on Miro.

- Each researcher was given three blue dots for the voting, and they placed a dot on the best ideas.

\section{Stage 4: prototype development}

- To build ideas for a lowfidelity prototype
- $\quad$ Each of the research members and the App developer was assigned roles to ensure the successful development of the low-fidelity prototype for the final day testing process.
- The most voted ideas were put together, and we had another round of voting where each researcher was given a pink dot, and the team leader was given three purple dots on the web-based board (Miro).

- $\quad$ The text and visual version of the storyboard was constructed as a group and through discussions on the web-based board (Miro) and Microsoft Teams.

On Figma, a prototype development site, the lowfidelity prototype was developed.

- $\quad$ Every researcher and the App developer completed their tasks (ie, content and language check) within Figma.

- $\quad$ Brainstorming of prompts for the testing day was conducted on Google Sheets among the researchers.

- Google sheet also was where a virtual scoreboard was set up for every researcher to capture the patient's evaluation of the prototype. 


\begin{tabular}{|c|c|c|}
\hline Stages and objectives & Process & Adaptations for web-based delivery of the workshop \\
\hline $\begin{array}{l}\text { To validate the solutions } \\
\text { for the patients through a } \\
\text { qualitative method }\end{array}$ & $\begin{array}{l}\text { - We tested the solutions to } 5 \text { patients using a con- } \\
\text { current think-aloud process. } \\
\text { We gathered verbal and visual feedback about } \\
\text { the low-fidelity prototype from the patients, } \\
\text { which we will use to build a high-fidelity proto- } \\
\text { type. }\end{array}$ & $\begin{array}{l}\text { - Interviews were conducted through Microsoft } \\
\text { Teams by a moderator, HS, with a patient observed } \\
\text { by other researchers (whose video and audio func- } \\
\text { tion was turned off). } \\
\text { HS and each patient could see each other for an } \\
\text { ice-breaking session at the start of the testing ses- } \\
\text { sion. This session was essential to create rapport } \\
\text { and to ensure the patient's readiness, mentally and } \\
\text { technically. } \\
\text { The patient was then given a link to the prototype } \\
\text { where they browsed through the prototype, gave } \\
\text { comments and answered prompted questions. The } \\
\text { patient's screen was shared within the MS Team. } \\
\text { The observers synchronously collected the patients' } \\
\text { replies on the utility and usability prompts about } \\
\text { the prototype during the interview on the virtual } \\
\text { scoreboard and the observer's field notes. } \\
\text { The moderator had accessed to the scoreboard and } \\
\text { would be able to pick up any point which needed } \\
\text { further clarification. } \\
\text { The interviews were audio recorded, and browsing } \\
\text { activities were video recorded. }\end{array}$ \\
\hline
\end{tabular}

The web-based workshop discussions were conducted on a web conference platform (Microsoft Teams), and brainstorming of the idea was conducted on a web-based board (Miro). While conducting the exercise on the web-based board, the workshop participants remained connected to the web conference site to allow ongoing discussion. The web-based board was superseded by a prototype development (Figma) site in stages 4 and 5, whereas discussions remained on Microsoft Teams. The app developer supported information technology activities. Two weeks before the workshop, one of the researchers contacted each of the participants (patients and HCPs) to assess technical skills such as the ability to log on, use a meeting platform, and logistic issues such as the quality of the internet connection.

\section{Setting}

The workshop, which took place between June 22 and 26, 2020, was conducted through a secure web-based meeting platform using a virtual whiteboard to facilitate information sharing between the researchers and app developers. Our original plan for a face-to-face workshop was changed to a web-based format to overcome the restriction of the order of movement because of the COVID-19 pandemic; an additional advantage was that it allowed participants from different locations and time zones to participate.

The patients were from 2 urban public primary care clinics in central Malaysia. Asthma is managed in primary care clinics, although chronic and acute care management through the provision of an asthma action plan to support asthma self-management is uncommon. Malaysia has a dual health system, public and private, where the public health system provides the leading service for the population with copayment of Ringgit Malaysia, RM 1 (US \$0.23) per visit.

\section{Samples and Recruitment}

\section{Stakeholder Discussion (Stage 1)}

A total of 3 patients and 2 HCPs who cared for asthma in the primary care settings, 2 app developers, 4 researchers from Universiti Putra Malaysia, and 1 from the University of Edinburgh were involved in the stakeholder discussion in stage 1 (Table 2).

Table 2. Summary of the stakeholders involved in each stage.

\begin{tabular}{|c|c|c|c|c|c|}
\hline \multirow[t]{2}{*}{ Stakeholder } & \multicolumn{5}{|c|}{ Stage } \\
\hline & 1 & 2 & 3 & 4 & 5 \\
\hline 1. Researchers & $\boldsymbol{\sigma}^{\mathrm{a}}$ & $\checkmark$ & $\checkmark$ & $\checkmark$ & $\checkmark$ \\
\hline 2. Patients & $\checkmark$ & & & & $\checkmark$ \\
\hline 3. Health care professionals & $\checkmark$ & & & & \\
\hline 4. App developers & $\checkmark$ & $\checkmark$ & $\checkmark$ & $\checkmark$ & $\checkmark$ \\
\hline
\end{tabular}

${ }^{\mathrm{a}}$ Stakeholder present.

\section{Testing of the Prototype (Stage 5)}

Five patients, recruited from the Klang Asthma Cohort, participated in testing the prototype at stage 5 (Table 2). The
Klang Asthma Cohort database is one of the research outputs of RESPIRE (National Institute for Health Research Global Health Research Unit on Respiratory Health) in Malaysia. The database contains 1280 people with asthma recruited from 
primary health care clinics in the Klang district. They provided consent to be called with invitations to participate in asthma-related research. Inclusion criteria for patients invited for this study were physician-diagnosed asthma, aged $>18$ years, smartphone user, limited health literacy, and were assessed by screening using the Bahasa Malaysia language version of the Health Literacy-Q47 scale [30]. The initial Health Literacy-Q47 scale [31] was translated and validated in Malaysia with a Cronbach $\alpha=.96$ [30].

\section{Data Collection}

Demographic information was collected from the database of patients who agreed to participate. Stakeholders' discussions in stage 1 focused on challenges by patients and HCPs around (1) asthma education, (2) asthma self-management, (3) monitoring of symptoms, (4) emotional support or lifestyle advice, (5) social support, and (6) clinic set up (Multimedia Appendix 1).

In stage 5 , we tested the prototype with 5 patients to assess its utility and usability using a set of semistructured questions in a concurrent think-aloud manner (Multimedia Appendix 2). During this session, HS, the main interviewer, guided the process. Four other researchers, PYL, SSG, ATC, and JW, observed the interview while the 2 app developers, Aidil Goh and Muhammad Marzuqi, managed the technical aspects of the sessions. The interviews took 1 hour and were conducted in Bahasa Malaysia, the patients' preferred language.

Qualitative interviews were audio recorded, other web-based discussions and browsing activities were video recorded, and web-based board exercises were captured and archived as described in Table 1. All interviews were transcribed verbatim.

\section{Data Analysis}

For this qualitative study, we used thematic analysis to obtain rich data from the stakeholders' discussions in stage 1 and the interviews in stage 5 . The texts were analyzed iteratively using a deductive thematic analysis approach, as outlined by Braun et al [32]. The deductive thematic analysis seeks to answer the researcher's theory or analytical interest within the topic [32]. Phases in the thematic analysis included [32] (1) familiarization with the data by reading and rereading and noting down initial ideas (memoing), (2) duplicate coding (HS and JW) of one interview and comparing decisions to agree on standardizing the coding framework before coding all the transcripts, (3) discussing emerging themes with the research team, (4) reviewing themes with the wider research team and generating a map of the analysis (HP, SSG, PYL, ATC, or IY), (5) defining themes iteratively, and (6) presenting the deductive analysis with a selection of extracts. The data were organized using NVivo 11 (QSR International) qualitative data analysis software (HP and IY).

\section{Results}

\section{Participants' Characteristics}

Five patients (including 3 who attended stage 1) attended stage 5 (prototype testing). Table 3 summarizes the demographics of the patients involved in stage 5 .

Table 3. Patients' demographic involved in stage 5.

\begin{tabular}{lllllll}
\hline ID & Age (years) & Gender & Education level & Health literacy score ${ }^{\text {a }}$ & $\begin{array}{l}\text { Use of pictorial asthma ac- } \\
\text { tion plan at } 6 \text { months }\end{array}$ & Access to a digital device \\
\hline P1 & 44 & Female & Secondary & 30 & Yes & Smartphone and PC \\
P2 & 36 & Male & Tertiary & 32 & No & Smartphone \\
P3 & 40 & Female & Tertiary & 17 & Yes & Smartphone and PC \\
P4 & 38 & Male & Tertiary & 21 & No & Smartphone \\
P5 & 19 & Male & Secondary & 31 & No & Smartphone and PC \\
\hline
\end{tabular}

${ }^{\mathrm{a}}$ Score less than 33 is considered as limited health literacy.

\section{The Outcomes of Each Stage}

\section{Stage 1: Understanding and Mapping Problems}

Overall, 3 patients and 2 HCPs (a family physician and a medical officer from Klang district) contributed to the stakeholder's discussion. The stakeholder discussion themes were categorized as relating to individuals, family and friends, society, and systems (Multimedia Appendix 3). The key problem used to inform the app design was education sources for asthma and support in the community, enabling self-management using pictorial action plans, reminders for medications, and asthma reviews or appointments. The log of history of asthma control, preventer intake, and information on expected best peak expiratory flow rate were features that could support patients during asthma review or appointment to discuss with their HCPs.

\section{Stage 2-4: Sketching, Designing, and Developing the Prototype}

Informed by the stakeholder discussion and findings of our previous qualitative study, we worked through the stages of sketching solutions and designed and developed the prototype (Multimedia Appendix 4). Through a round of voting in stage 3, solutions supporting self-management based on evidence-based practice were selected [3]. All winning solutions were clustered around four aspects of care: (1) education, (2) supporting self-management, (3) supporting behavior change, and (4) social support (Table 4). We created a storyboard for the prototype, and we developed the prototype app based on the storyboard, which was then tested in stage 5. 
Table 4. Asthma App content and design features.

\begin{tabular}{|c|c|c|}
\hline Main theme and section & Content & Features \\
\hline \multicolumn{3}{|l|}{ Education } \\
\hline $\begin{array}{l}\text { About asthma, its } \\
\text { symptoms and diagno- } \\
\text { sis; asthma medications }\end{array}$ & $\begin{array}{l}\text { Information in text and videos about asthma, symptoms, } \\
\text { triggers, how the diagnosis is made, exacerbations and myths } \\
\text { around asthma attack. Other information includes types of } \\
\text { medications used to treat asthma, its function, and potential } \\
\text { side-effects of the medications. There will be video-based } \\
\text { instructions on the inhaler technique. }\end{array}$ & $\begin{array}{l}\text { - The links to the Ministry of Health portal on } \\
\text { asthma was provided under specific headings } \\
\text { to facilitate the search for reliable information. }\end{array}$ \\
\hline \multicolumn{3}{|l|}{ Supporting self-management } \\
\hline $\begin{array}{l}\text { Self-monitoring of } \\
\text { symptoms }\end{array}$ & $\begin{array}{l}\text { - Patients indicate any experience of asthma symptoms in the } \\
\text { last } 24 \text { hours, which will translate into control and prompts } \\
\text { to check the action plan. }\end{array}$ & $\begin{array}{l}\text { Tick-box list of potential asthma symptoms; } \\
\text { ticking any one symptom will prompt a pop- } \\
\text { up on advice to look at an action plan with a } \\
\text { click button. }\end{array}$ \\
\hline Asthma action plan & $\begin{array}{l}\text { A pictorial asthma action plan was used. Illustrations and } \\
\text { wordings were validated in a series of discussions with } \\
\text { stakeholders. }\end{array}$ & $\begin{array}{l}\text { - List of zones are displayed, and patient choose } \\
\text { which zone are appropriate for them. }\end{array}$ \\
\hline \multicolumn{3}{|l|}{ Supporting behavior change } \\
\hline $\begin{array}{l}\text { Asthma medication and } \\
\text { appointment reminder }\end{array}$ & $\begin{array}{l}\text { - Patients provide information about medications and appoint- } \\
\text { ments which will trigger a reminder system at the timing of } \\
\text { choice. }\end{array}$ & $\begin{array}{l}\text { - Matrix of images of medications used and } \\
\text { drop-down menu for frequency and timing }\end{array}$ \\
\hline Asthma diary & $\begin{array}{l}\text { - Asthma control and medication uptake will be recorded in } \\
\text { the diary, including best PEFR }{ }^{\mathrm{a}} \text {. }\end{array}$ & $\begin{array}{l}\text { - Monthly calendar, which displays asthma } \\
\text { control and adherence }\end{array}$ \\
\hline Reward system & $\begin{array}{l}\text { - Achieving good asthma control and medication adherence } \\
\text { will be translated into points. }\end{array}$ & $\begin{array}{l}\text { - Display of scale of points achieved for good } \\
\text { asthma control and adherence }\end{array}$ \\
\hline \multicolumn{3}{|l|}{ Others } \\
\hline Social support & - Information regarding support groups for asthma in Malaysia & $\begin{array}{l}\text { - The links to various support groups available } \\
\text { in Malaysia }\end{array}$ \\
\hline
\end{tabular}

${ }^{\text {a}}$ PEFR: peak expiratory flow rate.

The entire process is illustrated in Figure 1, and the decisions on the prototype content are summarized in Table 4. The app was written in the Malay language. 
Figure 1. The Design Sprint process was undertaken on the web-based discussion board and meeting platform.

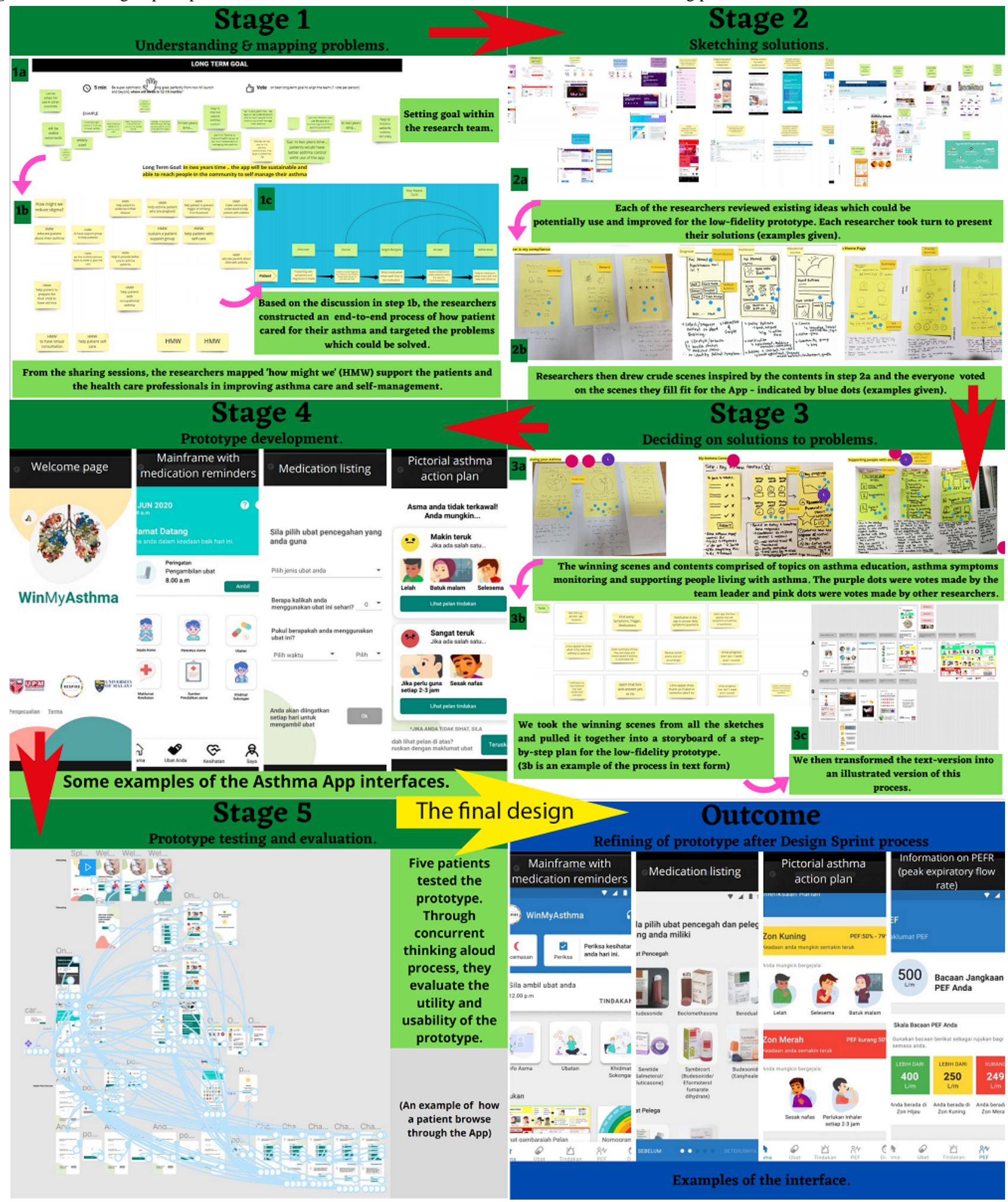

\section{Stage 5: Testing Low-Fidelity Prototype}

Patients who attended stage 1 , along with 2 other patients, attended stage 5 . Results are presented under the 2 main themes of utility (ie, app influence or support self-management) and usability (ease of use).

\section{Utility}

Patients commented that the app influenced the decision to self-manage in four ways: offering information, providing an

accessible asthma action plan, motivating and supporting improved medication adherence, and promoting behavior change through a reward system.

\section{Offering Information}

Patients considered that the app provided essential information regarding asthma and how to manage it. P4 explained, "the information about asthma in the App is interesting and informative." Although many were comfortable reading 
text-based information, some preferred audio-visual formats such as videos. P5 explained, "the information about asthma, maybe it can be in the video, it's more interesting than just text."

\section{Providing Accessible Asthma Action Plans}

Patients felt that having an action plan on the phone made the plan accessible when needed. As P1 described, "when you need the plan, you just open the App in your phone and click on the plan [action], to see it." In this format, patients considered it easier to access and use the app-based plan than the paper-based action plan, which they may not carry unless they attend medical appointments.

\section{Motivating and Supporting Improved Medication Adherence}

The medication reminder function of the app was viewed as a good support for achieving good adherence to daily preventers. P5 stated, "It will be difficult not to remember taking the medications because of the reminder, and because I use the phone frequently, it is hard to ignore the reminder (chuckled)."

\section{Promoting Behavior Change Through a Reward System}

The app was designed to encourage behavior change through a positive reward system, where good asthma control and adherence to twice daily preventive inhalers would be awarded points, and the cumulative points were visualized clearly. Patients liked this approach. P1 was incredibly excited to see the reward points on the app: "wow, there is a reward points, this is great!" This excitement was shared with other patients who preferred to see the tangible results of their actions. P3 elaborated on how the reward system could influence behavior:

That's nice when I get points for taking the medications. I do want to see that I accumulate points and the scale moved further. And I can only do this if my control is good and if I take my medications.

\section{Usability}

The patients could easily comprehend the information and instructions in the app. P2 elaborated on how he achieved this: "the instructions are accompanied with illustrations. It makes it easier to understand it." Although patients liked the use of illustrations and fewer words, the small font size used was challenging for some. P1 said:

$$
\begin{aligned}
& \text { [The] writing is small. I tried to put on my glasses, I } \\
& \text { still can't see it (chuckled). }
\end{aligned}
$$

We used cartoon-based illustrations of the medications and in the steps of the asthma action plan. Some studies have suggested that the pictorial asthma action plan may be useful for patients with asthma other than adults. P3 suggested:

\section{I think the illustrated plan can be appealing and useful for children and their carer. It's very easy to understand.}

Patients pointed out that a lack of navigational symbols meant that it was not always clear how to move from one interface to another. P4 stated his confusion:

There is no sign or indication on what to do next. I was a bit lost on what should I do now. Perhaps an arrow would help to tell that I can move forward.

Otherwise, patients were mostly satisfied with the simple layout. P1 gave an example of this:

\section{In terms of the layout, it's quite easy to navigate around the App. It's ok for me.}

The time spent using the app varied between 10 and 45 minutes. Some (younger) patients seemed comfortable navigating from one interface to the other and were keen to click buttons to explore the app functions. In contrast, others were dependent on symbols or prompted to navigate, which the app lacked at the testing stage.

The language used in the app was generally satisfactory, although there was a linguistic misunderstanding of breathlessness and wheeze in the Bahasa Malaysia language. P4 described his confusion on the Bahasa Malaysia words for breathlessness and wheeze:

\section{Mengalami sesak nafas (breathlessness) and lelah (wheezing), are different? I thought it's the same thing?}

\section{After the Workshop}

The design was refined and finalized after testing in stage 5 (Figure 2). 
Figure 2. The finalized app design.

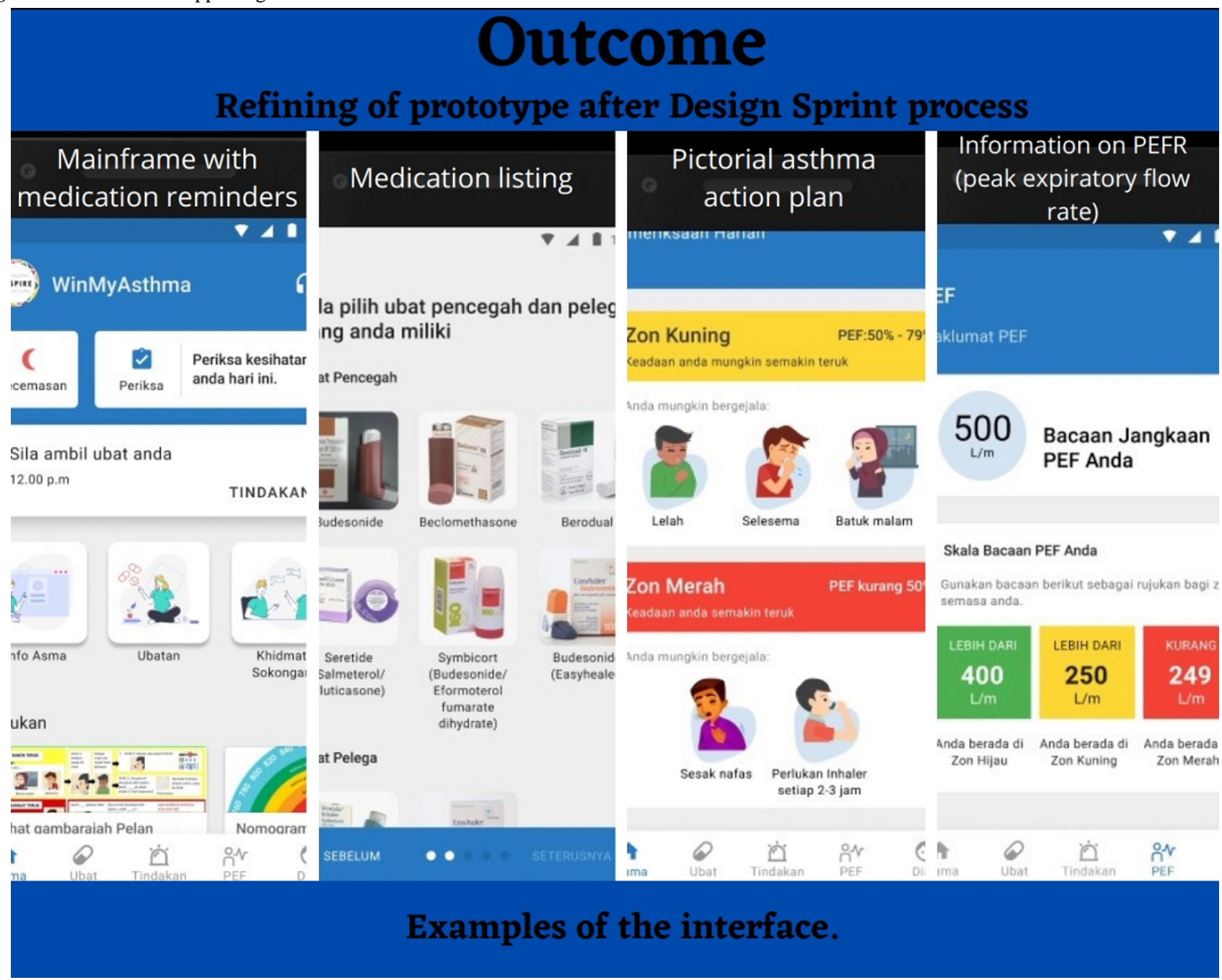

\section{Discussion}

\section{Principal Findings}

We conducted a design sprint workshop and employed a web-based format to ensure the safety of researchers and patients during the global pandemic. In this 5-stage workshop, we developed a low-fidelity prototype based on theoretical frameworks and refined it based on patient feedback during the design and testing stages. Patients described the resultant app to influence their ability to self-manage in four ways: offering information, providing accessible asthma action plans, motivating and supporting improved medication adherence, and promoting behavior change through a reward system. Specific usability issues were related to navigation, comprehension, and layout.

\section{Strengths and Limitations}

The involvement of stakeholders and the multidisciplinary approach at the development stage in the design sprint process are among the strengths of this study, which may increase the chances of the intervention meeting the needs of the target population. The 5-stage design sprint structure allowed the development and testing process to be performed quickly and efficiently at a low cost, which would likely be favorable in low-resource settings. Constructing a low-fidelity prototype offers many advantages in the initial stages of prototype development. It allows a quick gathering of requirements, ideas, and concepts and can be built rapidly [29]. The disadvantage was that the low-fidelity prototype lacked some core functionality (such as navigation features), so that the patients on day 5 gave feedback on a limited version of the app. Nevertheless, the feedback was beneficial and enabled the app to be refined after the workshop to produce a high-fidelity prototype.

The web-based approach connected people in different geographical locations and ensured safety during the global pandemic. We recognized that we do not have any participants aged $>50$ years, perhaps because this approach may be more appealing to younger age groups, although with limited health literacy, and it may not reflect the feasibility of using web-based methods for older age groups. We overcame limited internet access by providing an internet data voucher; however, we had to exclude those with no access to any digital devices. We provided training on the various platforms to be used in the workshop, thus overcoming the lack of digital skills. These strategies may assure researchers or intervention developers working in countries or settings with high levels of limited health literacy that this web-based methodology is of value. 
The pandemic context may have explained the relatively small number of participants recruited during the testing stage. Some participants found it challenging to commit uninterrupted time to a web-based workshop while being locked down at home with their domestic or caring or home-schooling responsibilities. For comparison, face-to-face intervention design workshops have been reported with 14 participants in 5-day workshops [33] and 38 participants over 6 weeks [34].

\section{Adaptation of the Design Sprint Workshop to a Web-Based Format}

Patients with asthma and HCPs were recruited for a workshop in March 2020, but this could not occur because of the compulsory lockdown imposed by the local authorities in response to the COVID-19 pandemic. Therefore, we adapted the workshop to the challenges of a web-based format and its potential impact on participants' research experience [35]. A high-speed internet connection and technical skills in conducting this workshop were vital. To overcome some of these practical issues, we supported all participants with mobile web-based access through an RM 10 (US \$2.42) internet data voucher to ensure that the participants would not bear the cost of internet access. Participants' experience with technologies was around social media, that is Facebook, video call, that is, WhatsApp, and information searching platforms, that is, Google and YouTube. We found a lack of experience with videoconferencing platforms and the software we planned to use during the testing day. Thus, we conducted training sessions for all participants to avoid technical problems during the workshop.

In the context of interviews, the literature suggests that web-based data collection can produce data of similar quality to face-to-face interviews [35]. Although using a web-based platform to interview patients was a new experience for the researchers, we found that the web-based programs eased discussions, and interviews took place quickly and effectively. Compared with traditional qualitative interviews, one advantage was that other researchers could observe the interview sessions on the web-based platform, and they could make concurrent fieldnotes. From the patient's feedback, although they knew they were being observed by additional researchers, being at their own home helped them forget about being observed and anxious.

In web-based discussions and interviews, dictation software has been used to capture audio data in text format, thereby avoiding transcription errors [36,37]. However, this was not possible in our context because the medium of interaction was the Bahasa Malaysia language, and the extensive use of colloquial language made it impossible to use any dictation software. Conducting research on the web raises concerns about participants' confidentiality and data security. We ensured that entry to the workshop was password-protected to control access to maintain the participant's confidentiality securely. The recordings were stored in a secure manner. For example, files from the workshop were encrypted and stored in a secure research data storage facility.

\section{Web-Based Design Workshop and the Context of Limited Health Literacy in a Low-to-Middle-Income Country}

Our app focused on designing a pictorial asthma action plan as a core strand of tailoring supported self-management for people with limited health literacy. Other features were a simple language for symptom assessment, education and information resources, provision of visual and audio medication reminders, and practical behavior change strategies such as a reward system. A clear message from our previous qualitative work was that participants wanted an interactive approach to support an asthma action plan with few words and clear pictures. Our original plan was to provide a paper-based pictorial action plan, but as it is not interactive, we reconsidered potential formats and decided to deliver the pictorial asthma action plan using a mobile app. Using a mobile app was seen as promoting a sense of autonomy to feel empowered in managing asthma.

Although previous reviews have reported a lack of interest in action plans [21], others have reported on the keenness of people to use action plans in mobile apps [38], although none have explored plans tailored for people with limited health literacy or the innovative pictorial representation of actions in a mobile app. In the United States, a study found that action plans were written at the literacy level of sixth-grade (11- to 12-year-olds), which will be a challenge to those without formal education or only receiving primary school education [39]. The same study also found that more graphics within an action plan may be needed to increase the ease of use [39]. In our web-based design workshop, the extensive use of images, icons, and the use of simple language were among the strategies used to overcome the challenge of understanding a written asthma action plan.

\section{Recommendations for Practice, Policy, and Research}

We outlined recommendations for practice, policy, and research based on this study in Textbox 1. On a practical level, to help researchers' concentration throughout the 5 days of the 7-hour workshops, we included frequent breaks and provided high-energy snacks. Each session was either 1 hour long with a 15-minute break or 45 minutes long with a 10-minute break. Committing to time in a workshop alone in front of the monitor can be challenging and mentally draining, so a week before the workshop, each researcher received a supply of high-energy snacks through the post. We also provided colored sticky notepads and permanent markers with similar tip sizes to ensure that all scanned sketches and writings were clear when uploaded on the web-based discussion board. 
Textbox 1. Recommendations for practice, policy, and research.

Practice

- Although some participants only join the workshop for short periods, researchers and technical colleagues have to concentrate on the web for long periods. Adequate breaks, attention to nutrition, and general comfort are essential.

- The web-based platforms may be unfamiliar to many participants; training before the workshop gives confidence and helps reduce technical problems on the day.

- $\quad$ Owing to the relatively low cost and a short time spent from development to testing, the web-based design sprint methodology may be suitable for low-resource settings.

- $\quad$ Remote conduct ensured that high-risk stakeholders were shielded during a pandemic and overcame geographical barriers.

Policy

- $\quad$ The process is a sprint so that the end product can be developed to a short timescale to meet pressing deadlines.

Research

- The feasibility study of conducting a more extensive scale web-based intervention design program is necessary to ensure its practicality.

\section{Conclusions}

Working with people with limited health literacy enabled the development of an app that could support them in self-managing their asthma. Specific components included sources of information on asthma, pictorial asthma action plan, simple language, audio-visual prompts, and rewards for supporting adherence to daily therapy and scheduled reviews. Despite practical challenges, a 5-day web-based design workshop proved to be manageable, enabling meaningful engagement from patients and HCPs so that a prototype is now ready for feasibility testing.

\section{Acknowledgments}

This research was commissioned by the UK RESPIRE using UK Aid from the UK Government. The views expressed in this publication are those of the authors and not necessarily those of the National Institute for Health Research or the UK Department of Health and Social Care. The RESPIRE collaboration comprises UK grant holders, partners, and research teams as listed on the RESPIRE website. The authors are grateful to the study subjects for participating in this study. The authors would like to thank the experts from Pocket Pixel Sdn Bhd, Mohd Khalid IA, Goh A, and Zainal MM for their support in the conduct of this study.

\section{Authors' Contributions}

HS, HP, PYL, SSG, and IY were involved in formulating the ideas for the study. HS and JW planned and conducted training for the participants. HS, PYL, SSG, ATC, and JW conducted the workshop and collected the data. HS conducted data analysis, and all authors were involved in data interpretation. HS drafted the manuscript. All authors critically revised the manuscript for intellectual content. All authors read and approved the final manuscript.

\section{Conflicts of Interest}

None declared.

\section{Multimedia Appendix 1}

Prompts for stakeholder discussion.

[DOCX File, 22 KB-Multimedia Appendix 1]

\section{Multimedia Appendix 2}

Utility and usability prompts.

[DOCX File , 21 KB-Multimedia Appendix 2]

\section{Multimedia Appendix 3}

Themes from the stakeholders' discussion. [DOCX File , 25 KB-Multimedia Appendix 3] 


\section{Multimedia Appendix 4}

Stages 2-4.

[DOCX File, 86 KB-Multimedia Appendix 4]

\section{References}

1. Pinnock H, Parke HL, Panagioti M, Daines L, Pearce G, Epiphaniou E, PRISMS and RECURSIVE groups. Systematic meta-review of supported self-management for asthma: a healthcare perspective. BMC Med 2017 Mar 17;15(1):64 [FREE Full text] [doi: 10.1186/s12916-017-0823-7] [Medline: 28302126]

2. Pinnock H, Epiphaniou E, Pearce G, Parke H, Greenhalgh T, Sheikh A, et al. Implementing supported self-management for asthma: a systematic review and suggested hierarchy of evidence of implementation studies. BMC Med 2015 Jun 01;13(1):127 [FREE Full text] [doi: 10.1186/s12916-015-0361-0] [Medline: 26032941]

3. Taylor S, Pinnock H, Epiphaniou E, Pearce G, Parke H, Schwappach A. A rapid synthesis of the evidence on interventions supporting self-management for people with long-term conditions: PRISMS-Practical systematic review of self-management support for long-term conditions. Health Serv Del Res 2014:02530. [doi: 10.3310/hsdr02530] [Medline: 25642548]

4. Sulaiman N, Aroni R, Thien F, Schattner R, Simpson P, Del Colle E, et al. Written Asthma Action Plans (WAAPs) in Melbourne general practices: a sequential mixed methods study. Prim Care Respir J 2011 Jun 18;20(2):161-169 [FREE Full text] [doi: 10.4104/pcrj.2011.00010] [Medline: 21336464]

5. Ställberg B, Lisspers K, Hasselgren M, Janson C, Johansson G, Svärdsudd K. Asthma control in primary care in Sweden: a comparison between 2001 and 2005. Prim Care Respir J 2009 Dec;18(4):279-286 [FREE Full text] [doi:

10.4104/pcrj.2009.00024] [Medline: 19455269]

6. Wiener-Ogilvie S, Pinnock H, Huby G, Sheikh A, Partridge MR, Gillies J. Do practices comply with key recommendations of the British Asthma Guideline? If not, why not? Prim Care Respir J 2007 Dec 21;16(6):369-377 [FREE Full text] [doi: 10.3132/pcrj.2007.00074] [Medline: 18026674$]$

7. Levy M, Andrews R, Buckingham R, Evans H, Francis C, Houston R. Why asthma still kills: the National Review of Asthma Deaths (NRAD). Royal College of Physcians. 2015. URL: https://www.rcplondon.ac.uk/projects/outputs/ why-asthma-still-kills [accessed 2021-08-05]

8. Sørensen K, Van den Broucke S, Fullam J, Doyle G, Pelikan J, Slonska Z, (HLS-EU) Consortium Health Literacy Project European. Health literacy and public health: a systematic review and integration of definitions and models. BMC Public Health 2012 Jan 25;12(1):80 [FREE Full text] [doi: 10.1186/1471-2458-12-80] [Medline: 22276600]

9. Eckman MH, Wise R, Leonard AC, Dixon E, Burrows C, Khan F, et al. Impact of health literacy on outcomes and effectiveness of an educational intervention in patients with chronic diseases. Patient Educ Couns 2012 May;87(2):143-151. [doi: 10.1016/j.pec.2011.07.020] [Medline: 21925823]

10. Federman AD, Wolf MS, Sofianou A, O'Conor R, Martynenko M, Halm EA, et al. Asthma outcomes are poor among older adults with low health literacy. J Asthma 2014 Mar 14;51(2):162-167. [doi: 10.3109/02770903.2013.852202] [Medline: 24102556]

11. National Health and Morbidity Survey 2015. 2015. URL: http://www.iku.gov.my/nhms/ [accessed 2021-06-10]

12. Lee $\mathrm{P}, \mathrm{Khoo}$ E. How well were asthmatic patients educated about their asthma? A study at the emergency department. Asia Pac J Public Health 2004 Jun 30;16(1):45-49. [doi: 10.1177/101053950401600108] [Medline: 18839867]

13. Zainudin BM, Lai CK, Soriano JB, Jia-Horng W, De Guia TS, Asthma Insights Reality in Asia-Pacific (AIRIAP) Steering Committee. Asthma control in adults in Asia-Pacific. Respirology 2005 Nov;10(5):579-586. [doi:

10.1111/j.1440-1843.2005.00753.x] [Medline: 16268910$]$

14. Salim H, Ghazali SS, Lee PY, Cheong A, Harrun NH, Isa SM, et al. Health literacy levels and its determinants among people with asthma in Malaysian primary healthcare settings: a cross-sectional study. BMC Public Health 2021 Jun 22;21(1):1186 [FREE Full text] [doi: 10.1186/s12889-021-11194-w] [Medline: 34158013]

15. Gordon NP, Crouch E. Digital information technology use and patient preferences for internet-based health education modalities: cross-sectional survey study of middle-aged and older adults with chronic health conditions. JMIR Aging 2019 Apr 04;2(1):e12243 [FREE Full text] [doi: 10.2196/12243] [Medline: 31518291]

16. Hopkins J. Networked individualism and networked families in Malaysia. In: Cabañes JV, Uy-Tioco CS, editors. Mobile Media and Social Intimacies in Asia. Dordrecht: Springer; 2020:31-45.

17. Golinelli D, Boetto E, Carullo G, Nuzzolese AG, Landini MP, Fantini MP. Adoption of digital technologies in health care during the COVID-19 pandemic: systematic review of early scientific literature. J Med Internet Res 2020 Nov 06;22(11):e22280 [FREE Full text] [doi: 10.2196/22280] [Medline: 33079693]

18. Malaysian Communications and Multimedia Commission Annual Report 2017. Ministry of Communications and Multimedia Malaysia, Putrajaya. 2020. URL: https://www.mcmc.gov.my/en/about-us/annual-reports/annual-reports\# [accessed 2021-08-12]

19. Lee HY, Jin SW, Henning-Smith C, Lee J, Lee J. Role of health literacy in health-related information-seeking behavior online: cross-sectional study. J Med Internet Res 2021 Jan 27;23(1):e14088 [FREE Full text] [doi: 10.2196/14088] [Medline: 33502332] 
20. Wu AC. The promise of improving asthma control using mobile health. J Allergy Clin Immunol Pract 2016 Jul;4(4):738-739. [doi: 10.1016/i.jaip.2016.04.003] [Medline: 27393782]

21. Hui C, Walton R, McKinstry B, Vasileiou E, Pinnock H. What do people with asthma want to see in an asthma self-management app? A review of views expressed in online social discussion forums. In: Proeedings of the Health Informatics Conference. 2017 Presented at: Health Informatics Conference 2017; Oct 3-4, 2017; Edinburgh p. 1-7 URL: https://www.research.ed.ac.uk/en/publications/what-do-people-with-asthma-want-to-see-in-an-asthma-self-manageme

22. Hui CY, Walton R, McKinstry B, Pinnock H. Time to change the paradigm? A mixed method study of the preferred and potential features of an asthma self-management app. Health Informatics J 2020 Jun 13;26(2):862-879 [FREE Full text] [doi: $10.1177 / 1460458219853381]$ [Medline: $\underline{31195877]}$

23. Mendiola MF, Kalnicki M, Lindenauer S. Valuable features in mobile health apps for patients and consumers: content analysis of apps and user ratings. JMIR Mhealth Uhealth 2015 May 13;3(2):e40 [FREE Full text] [doi: 10.2196/mhealth.4283] [Medline: 25972309]

24. Jake-Schoffman D, McVay M. Using the Design Sprint process to enhance and accelerate behavioral medicine progress: a case study and guidance. Transl Behav Med 2021 May 25;11(5):1099-1106. [doi: 10.1093/tbm/ibaa100] [Medline: $\underline{33057685]}$

25. Global Initiative for Asthma - GINA. 2020. URL: https://ginasthma.org/ pocket-guide-for-asthma-management-and-prevention/ [accessed 2021-05-21]

26. British Thoracic Society. 2016. URL: https://www.brit-thoracic.org.uk/quality-improvement/guidelines/asthma/ [accessed 2021-05-03]

27. Knapp J, Zeratsky J, Kowitz B. Sprint: How to Solve Big Problems and Test New Ideas in Just Five Days. New York: Simon and Schuster; 2016:1-288.

28. Banfield R, Lombardo C, Wax T. Design Sprint: A Practical Guidebook for Building Great Digital Products. Sebastopol, California: O'Reilly Media; 2015:1-272.

29. Virzi R, Sokolov J, Karis D. Usability problem identification using both low- and high-fidelity prototypes. In: Proceedings of the SIGCHI Conference on Human Factors in Computing Systems. 1996 Presented at: CHI96: CHI '96 ACM Conference on Human Factors in Computing Systems; April 13 - 18, 1996; Vancouver British Columbia Canada p. 236-243. [doi: $10.1145 / 238386.238516]$

30. Duong TV, Aringazina A, Baisunova G, Nurjanah, Pham TV, Pham KM, et al. Measuring health literacy in Asia: Validation of the HLS-EU-Q47 survey tool in six Asian countries. J Epidemiol 2017 Feb;27(2):80-86 [FREE Full text] [doi: 10.1016/j.je.2016.09.005] [Medline: 28142016]

31. Sørensen K, Van den Broucke S, Pelikan JM, Fullam J, Doyle G, Slonska Z, HLS-EU Consortium. Measuring health literacy in populations: illuminating the design and development process of the European Health Literacy Survey Questionnaire (HLS-EU-Q). BMC Public Health 2013 Oct 10;13(1):948 [FREE Full text] [doi: 10.1186/1471-2458-13-948] [Medline: 24112855]

32. Braun V, Clarke V. Reflecting on reflexive thematic analysis. Qual Res Sport Exerc Health 2019 Jun 13;11(4):589-597. [doi: 10.1080/2159676X.2019.1628806]

33. Martinez W, Threatt AL, Rosenbloom ST, Wallston KA, Hickson GB, Elasy TA. A patient-facing diabetes dashboard embedded in a patient web portal: design sprint and usability testing. JMIR Hum Factors 2018 Sep 24;5(3):e26 [FREE Full text] [doi: 10.2196/humanfactors.9569] [Medline: $\underline{\text { 30249579] }}$

34. Pfisterer KJ, Boger J, Wong A. Prototyping the automated food imaging and nutrient intake tracking system: modified participatory iterative design sprint. JMIR Hum Factors 2019 May 09;6(2):e13017 [FREE Full text] [doi: 10.2196/13017] [Medline: $\underline{\text { 31094336] }}$

35. Seymour WS. In the flesh or online? Exploring qualitative research methodologies. Qual Res 2016 Aug 17;1(2):147-168. [doi: 10.1177/146879410100100203]

36. Adler CL, Zarchin YR. The "virtual focus group": using the Internet to reach pregnant women on home bed rest. J Obstet Gynecol Neonatal Nurs 2002 May;31(4):418-427. [doi: 10.1111/j.1552-6909.2002.tb00064.x] [Medline: 12146931]

37. Tuttas CA. Lessons learned using Web conference technology for online focus group interviews. Qual Health Res 2015 Jan 05;25(1):122-133. [doi: 10.1177/1049732314549602] [Medline: 25192765]

38. Tinschert P, Jakob R, Barata F, Kramer J, Kowatsch T. The potential of mobile apps for improving asthma self-management: a review of publicly available and well-adopted asthma apps. JMIR Mhealth Uhealth 2017 Aug 02;5(8):e113 [FREE Full text] [doi: 10.2196/mhealth.7177] [Medline: 28768606]

39. Yin HS, Gupta RS, Tomopoulos S, Wolf MS, Mendelsohn AL, Antler L, et al. Readability, suitability, and characteristics of asthma action plans: examination of factors that may impair understanding. Pediatrics 2013 Jan 03;131(1):116-126. [doi: 10.1542/peds.2012-0612] [Medline: 23209106]
Abbreviations
HCP: health care professional
RESPIRE: National Institute for Health Research Global Health Research Unit on Respiratory Health 


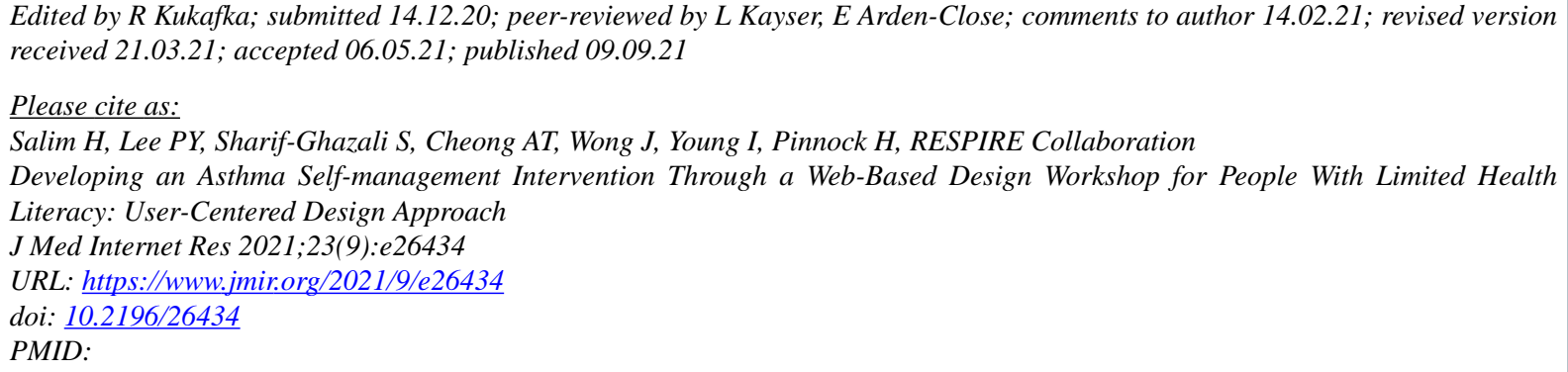

(CHani Salim, Ping Yein Lee, Sazlina Sharif-Ghazali, Ai Theng Cheong, Jasmine Wong, Ingrid Young, Hilary Pinnock, RESPIRE Collaboration. Originally published in the Journal of Medical Internet Research (https://www.jmir.org), 09.09.2021. This is an open-access article distributed under the terms of the Creative Commons Attribution License (https://creativecommons.org/licenses/by/4.0/), which permits unrestricted use, distribution, and reproduction in any medium, provided the original work, first published in the Journal of Medical Internet Research, is properly cited. The complete bibliographic information, a link to the original publication on https://www.jmir.org/, as well as this copyright and license information must be included. 